\title{
Trends of satellite derived chlorophyll-a (1997-2011) in the Bohai and Yellow Seas, China: Effects of bathymetry on seasonal and inter-annual patterns
}

\author{
Dongyan Liu ${ }^{\mathrm{a}, *}$, Yueqi Wang ${ }^{\mathrm{a}, \mathrm{b}}$ \\ ${ }^{\text {a }}$ Key Laboratory of Coastal Zone Environmental Processes and Ecological Remediation, Yantai Institute of Coastal Zone Research, Chinese Academy of Sciences, 264003 Yantai, \\ Shandong, PR China \\ ${ }^{\mathrm{b}}$ University of Chinese Academy of Sciences, 100049 Beijing, PR China
}

\section{A R T I C L E I N F O}

\section{Article history:}

Received 8 November 2012

Received in revised form 8 July 2013

Accepted 8 July 2013

Available online 19 July 2013

\begin{abstract}
A B S T R A C T
The spatial and temporal variability of sea surface chlorophyll-a (Chl-a) concentrations in the Bohai and Yellow Seas were analyzed, using satellite-derived Chl-a products from SeaWiFS and MODIS sensors over the period of September 1997-September 2011. A set of monthly and cloud-free Chl-a data was produced by the Data Interpolating Empirical Orthogonal Function (DINEOF) method. The results indicate that there are different Chl-a seasonal patterns existing in the Yangtze River mouth, coastal and offshore waters, respectively. In the Yangtze River mouth, a long-lasting Chl-a peak (May-September) is seen in summer. In coastal waters, two significant $\mathrm{Chl}$-a maxima occur in winter-spring and late summer, respectively. In offshore waters, only one significant spring (March-April) Chl-a maximum is evident with a time lag of 1-3 months to coastal waters and the signal of autumn maximum is very weak. In coastal waters, wind-tide-thermohaline circulations and East Asia summer rainy monsoon may important physical factors to impact the seasonal pattern of Chl-a, but increased human activity (e.g., eutrophication, dam) could significantly enhance this process. In offshore waters, the impact on the circulation of the YSWC in winter and YSCW in summer in the central Yellow Sea could be important physical factor in explaining the variability of Chl-a in seasonal patterns. The decadal trends of Chl-a and sea surface temperature are decreasing in coastal waters, with a significantly positive correlation. In offshore waters, the decadal trends of Chl-a is increasing but a slight decreasing sea surface temperature trend is seen, and they indicate a negative correlation.
\end{abstract}

(c) 2013 Elsevier Ltd. All rights reserved.

\section{Introduction}

Phytoplankton is a fundamental component of marine food webs, accounting for nearly $50 \%$ of global primary production (Field et al., 1998). The variability of phytoplankton impacts on the biogeochemical cycles and fishery production in marine ecosystems, and even the global climate processes (Chassot et al., 2010; Falkowski et al., 1998; Falkowski and Oliver, 2007). Chlorophyll-a (Chl-a) concentration is a good indicator of phytoplankton biomass. Gregg et al. (2005) used a 6-year time series of remotelysensed global ocean surface Chl-a (OSC) to evaluate recent trends and found that increased OSC values occurred in most coastal regions. This phenomenon is consistent with in situ observation of phytoplankton biomass in many coastal waters and the reason has been generally attributed to the overlapping effects of increasing anthropogenic activity (e.g., eutrophication) and climate

* Corresponding author. Address: Yantai Institute of Coastal Zone Research, CAS, 17th, Chunhui Road, Laishan District, 264003 Yantai, PR China. Tel./fax: +86 535 2109116.

E-mail address: dyliu@yic.ac.cn (D. Liu). change (e.g., sea temperature) (de Jonge et al., 2002; Harley et al., 2006; Smetacek and Cleorn, 2008). In contrast, OSC values displayed an decreasing trend in a few open oceans (e.g., North Pacific Ocean, North Atlantic Ocean) (Behrenfeld et al., 2006; Boyce et al., 2010; Gregg et al., 2005), and climate-driven increased sea surface temperature (SST) showed a strong correlation with the trend of declining OSC values in these open oceans (Boyce et al., 2010; Gregg et al., 2005). These results suggest the different forcing mechanisms for the Chl-a patterns in coastal and offshore waters.

The Bohai and Yellow Seas, located in the north of China, are connected by the Bohai Strait (Fig. 1a). The Bohai Sea is a shallow shelf sea, with an average water depth of $18 \mathrm{~m}$ and a total area of $77,000 \mathrm{~km}^{2}$. The Yellow Sea, located between China and the Korean Peninsula, has an average depth of about $50 \mathrm{~m}$, characteristic of a typical shallow epicontinental sea. Numerous rivers from the Chinese and Korea continents, including two of the largest rivers in the world(Yellow River and Yangtze River), flow into the Bohai and Yellow Seas (Fig. 1a) and provide substantial land-sourced nutrients for supporting high primary production and fisheries. Over the last decades, increased land-sourced nutrient input has 

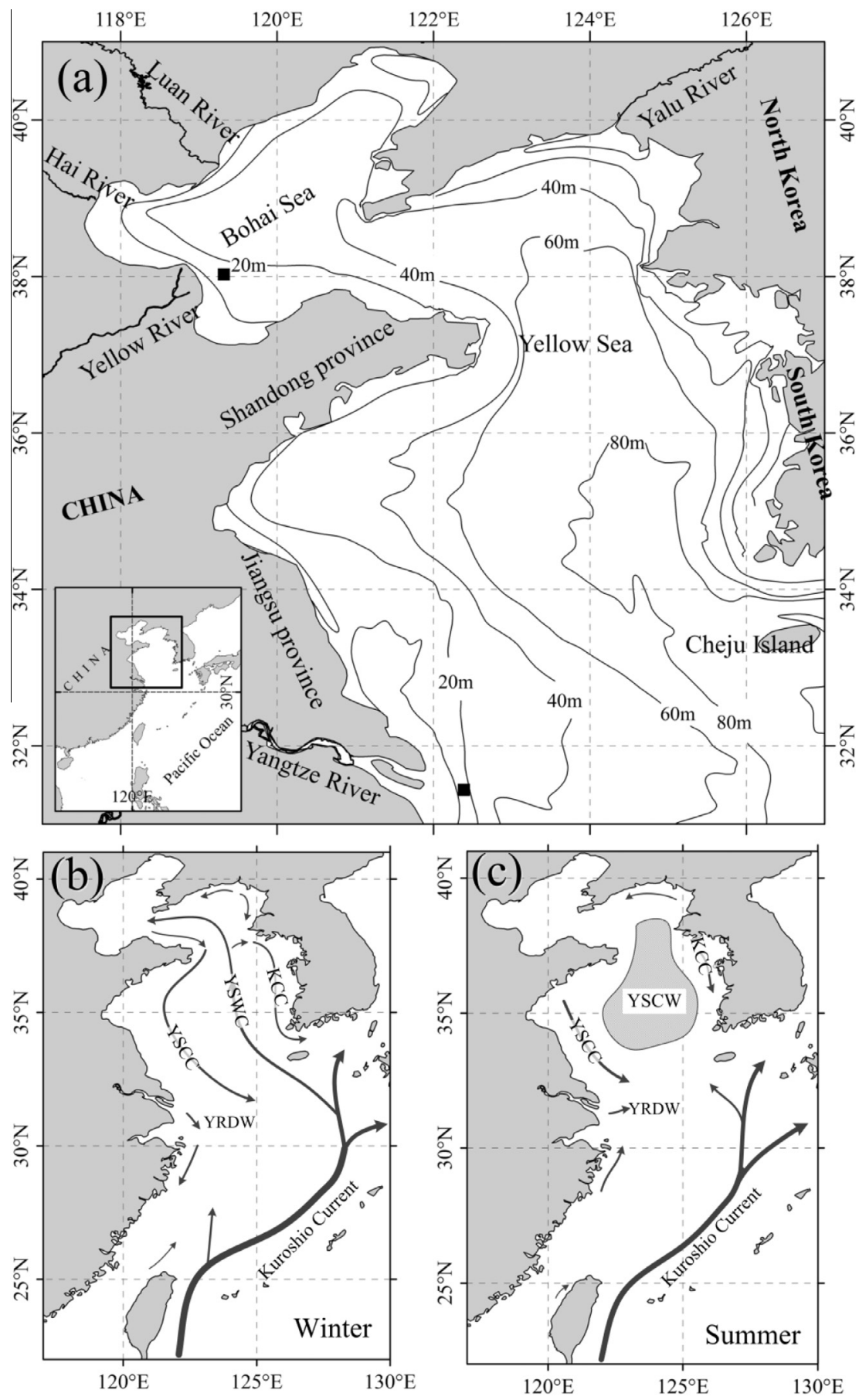

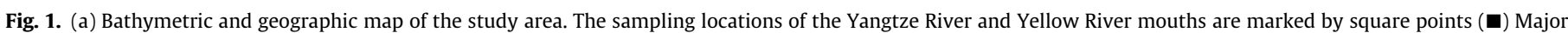

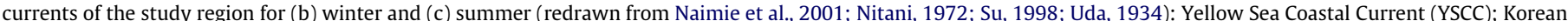
Coastal Current (KCC); Yellow Sea Warm Current (YSWC); Yellow Sea Cold Water (YSCW); Yangtze River Diluted Water (YRDW).

caused a remarkably high nitrogen concentration in the Bohai and Yellow Seas, and eutrophication has occurred in the large-river mouths and many coastal waters (Lin et al., 2005; Wang et al., 2003; Yu et al., 2000; Zhou et al., 2003).

Meanwhile, the Yellow Sea Warm Current (YSWC), with a warm and salty character, driven by the incursion of a branch of the Kuroshio subsurface water onto the shelf, flows into the Yellow Sea south of Cheju Island, Korea and has a strong impact on the hydrography and circulation in the Bohai and Yellow Seas, particularly in winter (Naimie et al., 2001; Nitani, 1972; Su, 1998) (Fig. 1b, c). In winter, strong and cold northwesterly winds can rap- idly decrease the SST in the Bohai and Yellow Seas and meanwhile drive coastal waters southward (Su, 1998). YSWC is observed as compensating current extending northward as far as the Bohai Sea during winter (Naimie et al., 2001). Because YSWC is subsurface warm water, the vertical exchange with cold surface seawater is also strong in winter. However, YSWC is very weak in summer (Fig. 1c), the water mass produced by winter cooling and vertical mixing thus remains in the deep central Yellow Sea, resulting in a basin-scale low-pressure system and cyclonic circulation called the Yellow Sea Cold Water mass (YSCW) (Naimie et al., 2001; Uda, 1934) (Fig. 1c). These physical processes can significantly 
impact the spatial and temporal variations of frontal structures, the redistribution of nutrients and the formation of the Chl-a pattern between coastal and offshore waters (Lie et al., 2009; Mask et al., 1998; Naimie et al., 2001).

Shelf and coastal fronts in the Bohai and Yellow Seas, arising from temperature and salinity variation, have been identified by using satellite data (Hickox et al., 2000; Huang et al., 2010). They follow the $50 \mathrm{~m}$ isobath and play key roles in nutrient transport and high productivity (Hickox et al., 2000; Huang et al., 2010; Liu et al., 2003). The strong convection currents between coastal and offshore waters formed in some seasons can enhance the coastal nutrient transporting to offshore waters (Yuan and Hsueh, 2010; Yuan et al., 2008). Liu et al. (2003) observed high primary and secondary production at Yellow Sea fronts and Huang et al. (2010) found a good match between the position of major spawning grounds and the position of coastal fronts. The variability of Chla between coastal and offshore waters may be responding to the variations in frontal structures on seasonal and inter-annual time scales. To know the answer, the comparison of Chl-a in a large spatial and temporal scale, at least at the decadal scale, is necessary.

It is quite challenging to collect large scale and continuous time-series Chl-a data from in situ observation alone, when we consider the variable marine environment, fast growing phytoplankton and high cost of cruises. The rapid development of satellite remote sensing technology has provided a useful complementary approach for us to acquire continuous and largescale satellite-derived OSC data, which can greatly enhance our understanding of the variability of $\mathrm{Chl}$-a from coastal to offshore waters in seasonal and inter-annual scales (e.g., Gregg et al., 2005, 2003; Navarro and Ruiz, 2006; Radiarta and Saitoh, 2008; Saitoh et al., 2002; Volpe et al., 2011). The Bohai and Yellow Seas experience high turbidity due to the large volume of sediment input from rivers. Coastal bathymetry and large river discharges are regarded as critical factors to affecting the spatial pattern of ocean color observation (Shi and Wang, 2012). Sediment re-suspension caused by wind and tidal currents can impact on the accuracy of satellite-derived Chl-a concentrations, particularly in coastal waters (Gong et al., 2003; Shi and Wang, 2010). Efforts have been made to improve the accuracy of satellite-derived Chl-a in local Case-II seawaters (Shi and Wang, 2012; Siswanto et al., 2011; Wang and Shi, 2007).

Although uncertainties still exist, some important ecological information has been distilled from satellite-derived Chl-a. For example, Tang et al. (2006) successfully analyzed the formation, distribution and advection of phytoplankton blooms in the Bohai Sea, using satellite SeaWiFS ocean color data; He et al. (2013) used a 14-years (1998-2011) time series of satellite ocean color data from SeaWiFS and MODIS to investigate the seasonal and inter-annual variability of phytoplankton blooms in the eastern China seas. They found that most of the blooms occurred in the spring (AprilJune) and summer (July-September), consistent with in situ observations (Gong et al., 2003; Tian et al., 2005; Zhou et al., 2003). Recently, Yamaguchi et al. (2012) analyzed the spatial and temporal variability of satellite-derived Chl-a in the Eastern China Seas. They found that a January-March Chl-a maximum usually occurred in the coastal waters of the Shandong and Jiangsu provinces, but an April Chl-a maximum occurred in the central Yellow Sea and East China Sea and a July maximum occurred near the Yangtze River mouth.

These results not only showed that satellite-derived Chl-a is useful in the Bohai and Yellow Seas, but also indicated the existence of different Chl-a patterns between coastal and offshore waters. In the study reported here, imagery from SeaWiFS and MODIS/Aqua between 1997 and 2011 in the Bohai and Yellow Seas were analyzed to determine the variability of $\mathrm{Chl}-\mathrm{a}$ at decadal scale. Over different depth ranges $(0-20 \mathrm{~m}, 20-40 \mathrm{~m}$ and $>40 \mathrm{~m})$, the seasonal and inter-annual patterns of Chl-a and SST were differentiated. The Yellow River and Yangtze River mouths as specific regions were distinguished separately. The correlations between Chl-a and SST were discussed by the regions, respectively, with an aim to knowing the different impacts between coastal waters and offshore areas.

\section{Materials and methods}

\subsection{Satellite data collection: Chl-a and SST}

Standard mapped satellite images $(120 \times 120$ pixels $)$ from SeaWiFS and MODIS/Aqua were used to derive surface Chl-a concentrations in the Bohai and Yellow Seas. Monthly averaged images between September 1997 and September 2011 for the geographic area $117-127^{\circ} \mathrm{N}$ by $31-41^{\circ} \mathrm{E}$ were used (Fig. 1a). These satellite images were obtained from the Ocean Biology Processing Group (OBPG) of the Goddard Space Flight Center (GSFC) (http://oceancolor.gsfc.nasa.gov/) in the compressed Hierarchical Data Format (HDF). The basic algorithm described by O'Reilly et al. (1998) was used for calculating Chl-a concentrations.

The daily optimum interpolation sea surface temperature (OISST, version 2) dataset produced by the NOAA National Climatic Data Center (NCDC, http://www.ncdc.noaa.gov/cdr/operationalcdrs.html) were processed. Version 2 of the OISST dataset is
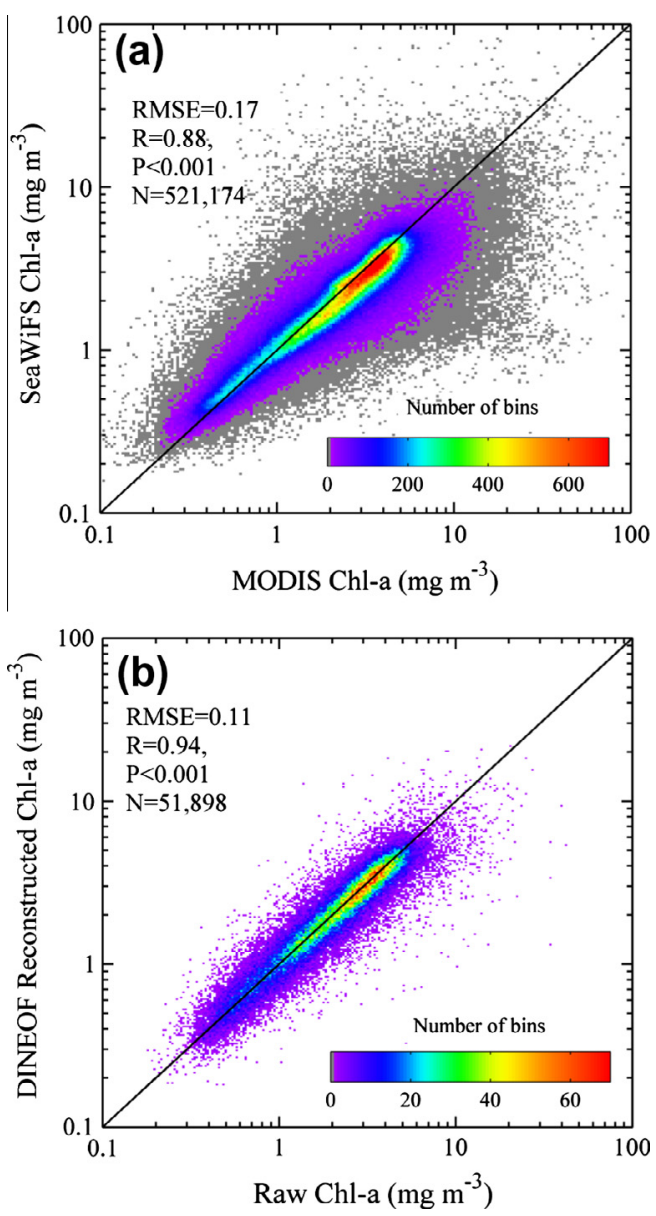

Fig. 2. Results of Chl-a data reconstruction. (a) SeaWiFS versus MODIS concurrent data for the whole study area during September 1997 to December 2010; (b) DINEOF reconstructed Chl-a values versus raw Chl-a values at the cross-validation points. Color scale indicates the density function. (For interpretation of the references to color in this figure legend, the reader is referred to the web version of this article.) 
available on a $0.25 \times 0.25$ grid at a temporal resolution of one day for the period from 1985 to present and is an improvement over the older weekly OISST dataset (Reynolds et al., 2007). In this paper, the SST dataset used spans from September of 1997 to September of 2011 , with the same domain $\left(117-127^{\circ} \mathrm{N}\right.$ by $\left.31-41^{\circ} \mathrm{E}\right)$ of the ocean color imagery (see above). These daily data were composited into monthly averages for matching with the Chl-a data.

\subsection{Data pre-processing and reconstruction}

All satellite Chl-a images were filtered to remove land and images with low pixel coverage $(<15 \%)$ were discarded. Images with 7579 pixels were used for data processing, which can account for $93.7 \%$ coverage of the sea area (totally 8089 pixels). The SeaWiFS images were directly replaced by the MODIS/Aqua images when there was no data coverage over the study period from September 1997 to September 2011. Finally, a total of 153 SeaWiFS images and 16 MODIS/Aqua images were used to construct a total of 169 monthly Chl-a images between September 1997 and September 2011. To validate the consistency between SeaWiFS Chl-a data and MODIS/Aqua Chl-a data in this study area, a linear comparison is given using concurrent data (Section 3.1).

Replacement of missing data due to clouds or malfunctions in each image was performed using the Data Interpolation Empirical Orthogonal Function (DINEOF) method (Alvera-Azcarate et al., 2005; Beckers et al., 2006; Beckers and Rixen, 2003), which is a self-consistent, parameter-free technique for gappy data reconstruction and is less computationally time intensive, especially for large data matrices with many gaps.

Since the satellite Chl-a values spanned three orders of magnitude and Chl-a retrievals are often log-normally distributed (Campbell, 1995), raw data were log-transformed prior to reconstruction in order to homogenize the variance and yield a near-normal data distribution. Processed data were stored in the initial $m \times n$ matrix, where $m$ is the number of pixels and $n$ is the number of images $(7579 \times 169$ in this study). Firstly, a random
$3 \%$ of the valid data in the matrix were set to zero in the initial matrix, and these values set aside for use in subsequent progressive cross-validation (see below). The temporal-spatial mean of the initial matrix was then calculated and subtracted from the initial matrix. Missing data was set to zero.

The first EOF decomposition was computed by the singular value decomposition (SVD) method, and the spatial EOF, singular values matrix and temporal EOF were obtained. Gaps in the data were filled by reconstructing the series using the EOFs:

$X_{i, j}=\sum_{p=1}^{k} S_{p}\left(U_{p}\right)_{i}\left(V_{p}^{T}\right)_{j}$

where $X_{i, j}$ is the missing data, $i$ and $j$ are the spatial and temporal indexes of the data, $U_{p}$ and $V_{p}$ are the $p^{\text {th }}$ column of the spatial and temporal EOF, respectively; $S_{p}$ is the $p^{\text {th }}$ singular value, and $k$ is the number of EOFs be used in the reconstruction.

Successive SVD decomposition was performed using the new guess matrix until the minimum root mean square error (RMSE) between the initial values and reconstructed values was obtained. In the initial step the first EOF mode is computed and using this all missing data is reconstructed, then the number of computed EOFs $(k)$ is increased by iteration until the minimum RMSE is obtained. The RMSE is defined as:

$$
\text { RMSE }=\sqrt{\frac{\sum[S-I]^{2}}{n}}
$$

where $S$ is original Chl-a value, $I$ is reconstructed Chl-a value and $n$ is the number of match-up samples.

Once the optimal number of EOFs is determined, the process is restarted, this time including the $3 \%$ cross-validation data we set aside before. Final values for the missing data are computed. This is a general description of how the method works. For a more detailed description, see Alvera-Azcarate et al. (2005) and Beckers and Rixen (2003).
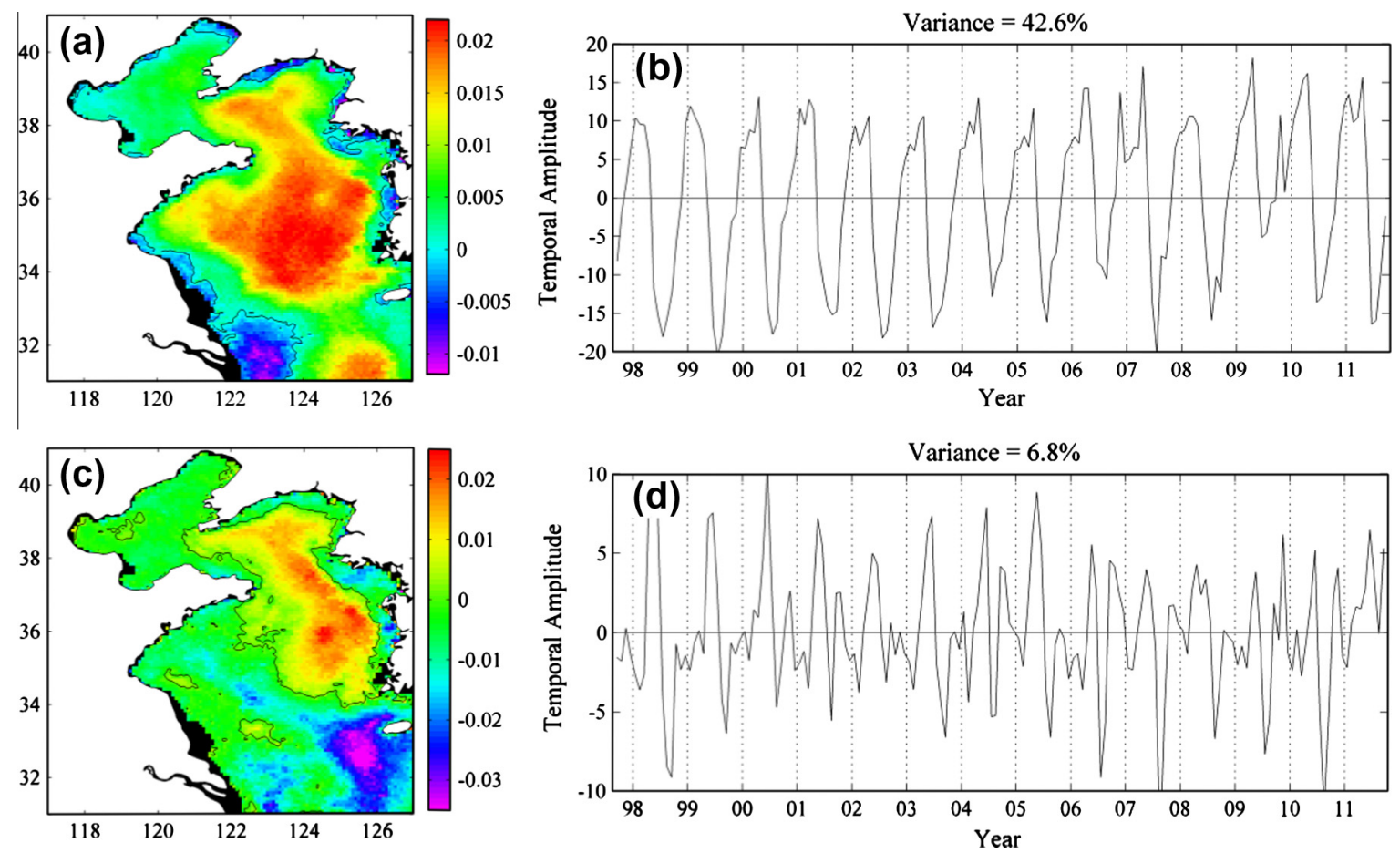

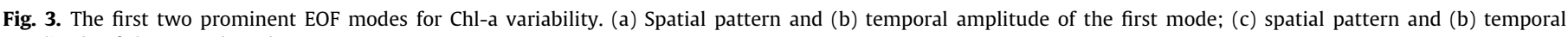
amplitude of the second mode. 

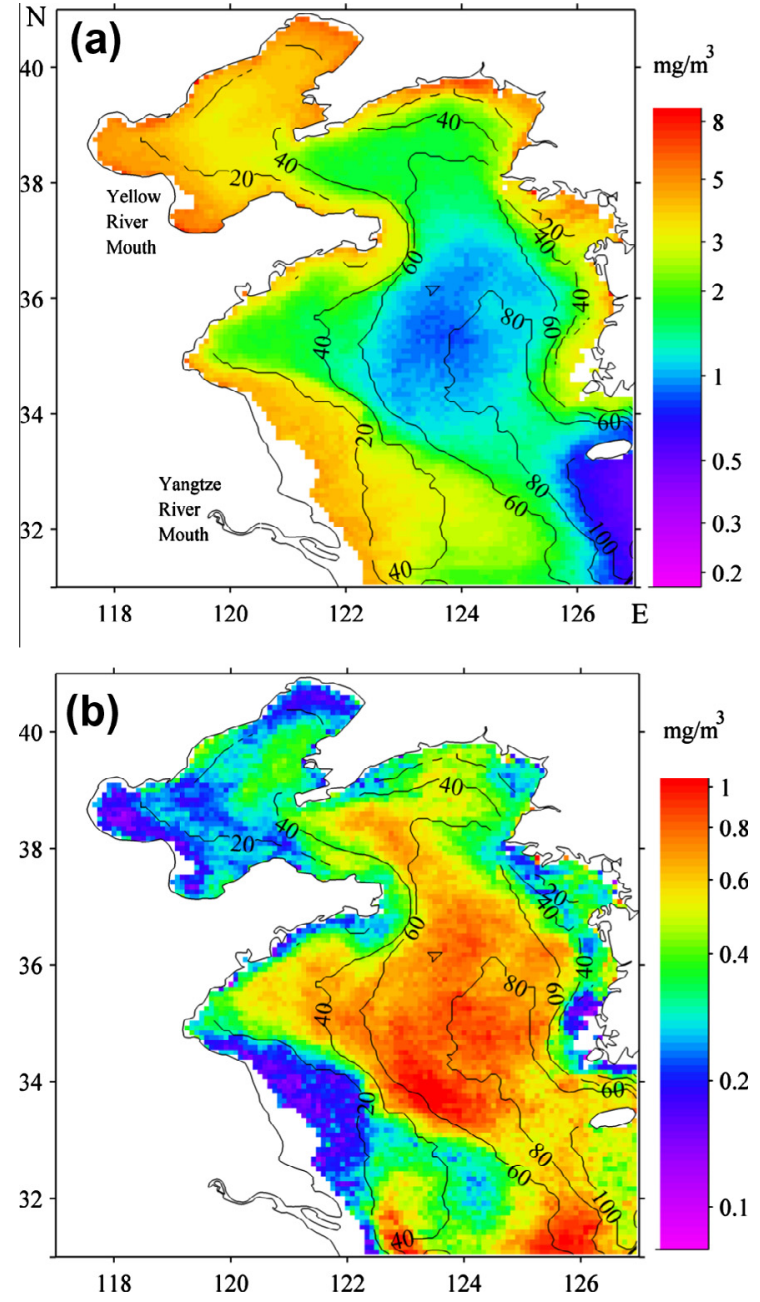

Fig. 4. (a) The temporal mean field image and (b) standard deviation image of Chl-a concentration over the whole study period. The isobaths are shown in meters.

\subsection{Statistical analysis}

After DINEOF reconstruction, the cloud-free Chl-a values were exponentially transformed before using for figures and statistical analysis. In this paper, quartile-based statistics are used to describe the characteristics and distribution of the Chl-a data, owing to its log-normal distribution (Campbell, 1995). The median was used to summarize the mean values of each distribution, because the median approximates the geometric mean of distribution and being robust to anomalously high or low Chl-a values, and the difference between the 75 th and 25 th percentile was used as measure of variability for each distribution and is analogous to standard deviation (STD) (Krishna, 2010; Zar, 1999). The STD was also scaled by its corresponding median before the comparison of variability over different locations or sub-regions.

The time series of the monthly percentage anomaly of Chl-a and SST obtained as follows: the monthly climatology values were obtained from the median of each corresponding month over the 14year Chl-a and SST data (1997-2011), and the percentage anomaly in each month was obtained as:

Anomaly $=\frac{S-C}{C} \times 100 \%$

where $S$ is the monthly value, $C$ is the mean of the corresponding monthly climatology value.

Linear regression was applied to the monthly anomalies using least-squares to summarize the inter-annual trend and intercept, and the statistical significance of the linear change was assessed with a statistical F-test. Pearson correlation analysis was used to detect the correlations between different parameters.

\section{Results}

\subsection{Result of satellite derived Chl-a reconstruction}

SeaWiFS Chl-a time series gaps were directly filled using the corresponding MODIS/Aqua Chl-a data to enlarge the Chl-a dataset series. A quantitative comparison between the SeaWiFS and the MODIS/Aqua data sets displayed a good correlation (Fig. 2a). The RMSE log difference of all concurrent data points between the two sensors is 0.17 , and the Pearson correlation coefficient is $0.88(P<0.001, N=521,174)$ and the scatter plot showing a near 1:1 linear plot (Fig. 2a). The cross-validation between DINEOFreconstructed Chl-a data and initial Chl-a data indicated that 24 modes were sufficient to reconstruct missing points, giving the highest Pearson correlation coefficient $0.94 \quad(P<0.001$, $N=51,898$ ) and the lowest RMSE log difference is 0.11 (Fig. 2b). These statistical results gave confidence for using the reconstructed cloud-free Chl-a data set to analyze the pattern of Chl-a in the studied sea areas.

\subsection{The dominant EOF modes of Chl-a data}

EOF analysis was performed after the Chl-a data were reconstructed by DINEOF. Prior to the EOF analysis, the temporal-spatial mean of each pixel was subtracted from the original dataset. Fig. 3 shows the first and second EOF modes, these two modes account for $49.4 \%$ of the Chl-a variability.
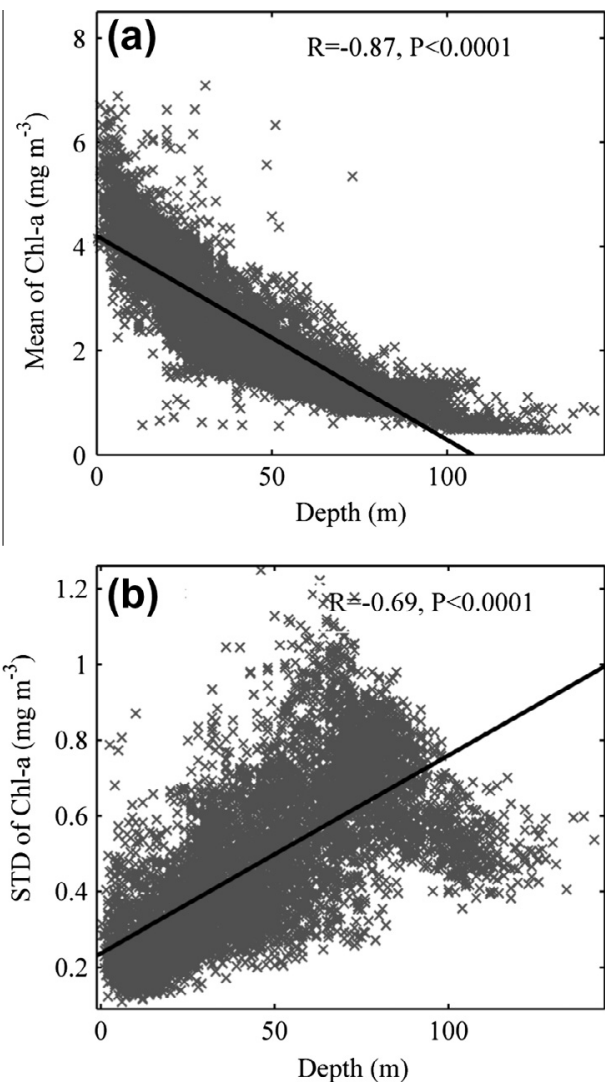

Fig. 5. (a) Scatter plot of the temporal mean of Chl-a concentrations and the sea water depth, (b) Scatter plot of Standard deviation of Chl-a concentrations and sea water depth. Solid lines indicate linear regression fit. 
The first EOF mode explains $42.6 \%$ of the total variance. The spatial pattern is dominated by positive signals, except for a few narrow bands near to the estuary and shore (Fig. 3a); the temporal amplitude shows positive values from winter to spring (November to April) but negative values from summer and autumn (June to October) (Fig. 3b). The result is related to the seasonal cycles, with high Chl-a concentration in the winter-spring in offshore waters and high Chl-a concentration in summer in coastal waters.

The second mode contains $6.8 \%$ of the total variance. The spatial pattern shows a remarkable positive signal (0.01 significant level) in the central Yellow Sea but the negative signal (0.01 significant level) dominates in other regions (Fig. 3c); the temporal amplitude of this mode exhibits a strong positive signal in spring (MarchApril) but negative in other months (Fig. 3d). This result indicates that a strong spring bloom occurred in the central Yellow Sea.

\subsection{Chl-a spatial distribution and variability in the Bohai and Yellow} Seas

The spatial pattern of Chl-a concentrations was produced by the temporal mean field of monthly data during 1997-2011 (Fig. 4a) and the variability was represented by the STD (Fig. 4b), respectively. One general spatial pattern evident is that mean Chl-a concentrations in the Bohai Sea are higher than in the Yellow Sea, and another is that mean Chl-a concentrations in coastal waters are higher than in offshore waters.

In a comparison, the characteristics of the Chl-a spatial distribution and variability in the Bohai and Yellow Seas appear to align with the isobaths of $0-20 \mathrm{~m}, 20-40 \mathrm{~m}$ and $>40 \mathrm{~m}$, respectively (Fig. 4a and b). It is noted that:

(1) The highest Chl-a values (3.0-5.0 $\mathrm{mg} \mathrm{m}^{-3}$ ) and the lowest variability (STD $<0.3 \mathrm{mg} \mathrm{m}^{-3}$ ) are observed in coastal waters, in the adjacent sea area of the Yangtze River and Yellow River mouths where the water depth is less than $20 \mathrm{~m}$.

(2) Compared with coastal waters and the sea adjacent to the large river mouths, the central Bohai Sea and the offshore waters of the Yellow Sea with the water depth of 20-40 m have lower Chl-a concentrations $\left(1.5-3.5 \mathrm{mg} \mathrm{m}^{-3}\right)$ but higher variability (STD $=0.4-0.6 \mathrm{mg} \mathrm{m}^{-3}$ ).

(3) In contrast to (1) and (2), the lowest Chl-a values $\left(0.5-2.0 \mathrm{mg} \mathrm{m}^{-3}\right.$, with most of values below $1 \mathrm{mg} \mathrm{m}^{-3}$ ) and the highest variability (STD $>0.8 \mathrm{mg} \mathrm{m}^{-3}$ ) occurred in the center Yellow Sea where the water depth with a range of $40-120 \mathrm{~m}$.
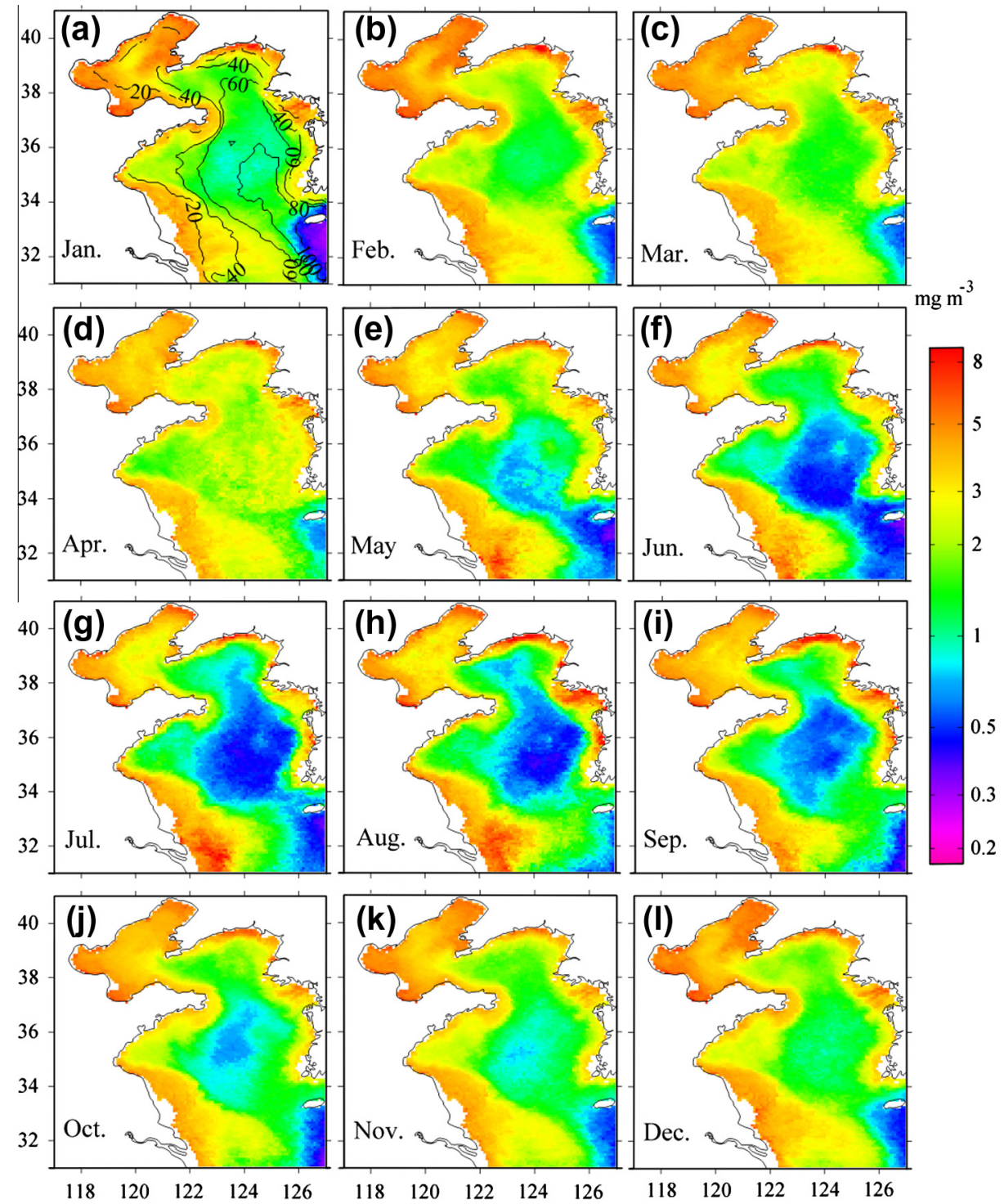

Fig. 6. Monthly climatological Chl-a concentration images in the study area for the period from September 1997 to September 2011. 
Linear statistical analysis further verifies the relationship between Chl-a and water depth (Fig. 5). Chl-a concentrations and water depths display a significant negative correlation $(R=-0.87$, $P<0.0001$ ) (Fig. 5a), and there is a significant positive correlation $(R=0.69, P<0.0001)$ between STD and water depths (Fig. 5b). These results indicated a significant spatial correlation between water depth and Chl-a concentrations.

3.4. Chl-a seasonal and inter-annual patterns in the Bohai and Yellow Seas

The seasonal pattern of Chl-a concentrations represented by climatological monthly images in each month from 1997 to 2011 is shown in Fig. 6. The seasonal dynamics of Chl-a in the Bohai and Yellow Seas result in a significant growth process in winter and spring (December-April) and an obvious depletion from late spring to early autumn (May-September) (Fig. 6). From the images of Chla concentrations during January-April (Fig. 6a-d), the maximum Chl-a in the central Yellow Sea occurs later than in coastal waters and the Bohai Sea.

To gain more insight of Chl-a seasonal variations in different sea regions, the Bohai and Yellow Seas were divided into five regions following three water depths ( $<20 \mathrm{~m}, 20-40 \mathrm{~m}$ and $>40 \mathrm{~m}$ ) and two large river mouths (Yangtze and Yellow Rivers) (Fig. 7). The comparison of the results showed that:

(1) In coastal waters with water depth of $<20 \mathrm{~m}$, the seasonal pattern of Chl-a concentrations show two maxima in the 14-year averaged data (Fig. 7a). One occurs in winter or spring (December-March); the other maximum often shows in August (late summer) and the values sometimes are higher than the winter-spring values (Fig. 7a).

(2) Compared with the Chl-a pattern in (1), a similar pattern occurs in the sea areas with water depth of $20-40 \mathrm{~m}$. However, there are still some small different variations. Chl-a maximum dominates in March and August-maximum only occurs in some years (Fig. 7a).

(3) A very different Chl-a seasonal pattern occurs in the sea area with water depth $>40 \mathrm{~m}$. Chl-a maximum dominates in April and no August-maximum occurs (Fig. 7a).

(4) The sea region near to the Yangtze River mouth is characterized by a long-lasting summer Chl-a maximum which starts in May and ends in August (Fig. 7b); the Chl-a seasonal pattern near to the Yellow River mouth basically matches the pattern in coastal waters $(<20 \mathrm{~m}$ ) (Fig. $7 \mathrm{a}$ and b) but has a significant summer minimum.

Chl-a inter-annual variations during 1998-2011 also displayed different patterns for the isobaths classes (Fig. 8):

(1) In the sea region with water depth of $<20 \mathrm{~m}$, the interannual pattern for the Chl-a anomaly displayed a decreasing trend since 1998 (Fig. 8a).

(2) In the sea region with the water depth of 20-40 m, the interannual pattern for the Chl-a anomaly displayed a slight increasing trend (Fig. 8b).

(3) In the sea region with the water depth $>40 \mathrm{~m}$, the interannual pattern of Chl-a anomaly displayed a significant increasing trend (Fig. 8c).

\subsection{SST seasonal and inter-annual patterns in the Bohai and Yellow} Seas

Monthly averaged SST displays a general temperate climate, with a maximum in summer (August: $25-27^{\circ} \mathrm{C}$ ) and minimum in winter (February: $5-10^{\circ} \mathrm{C}$ ) (Fig. 9a). In spatial scale, the south-
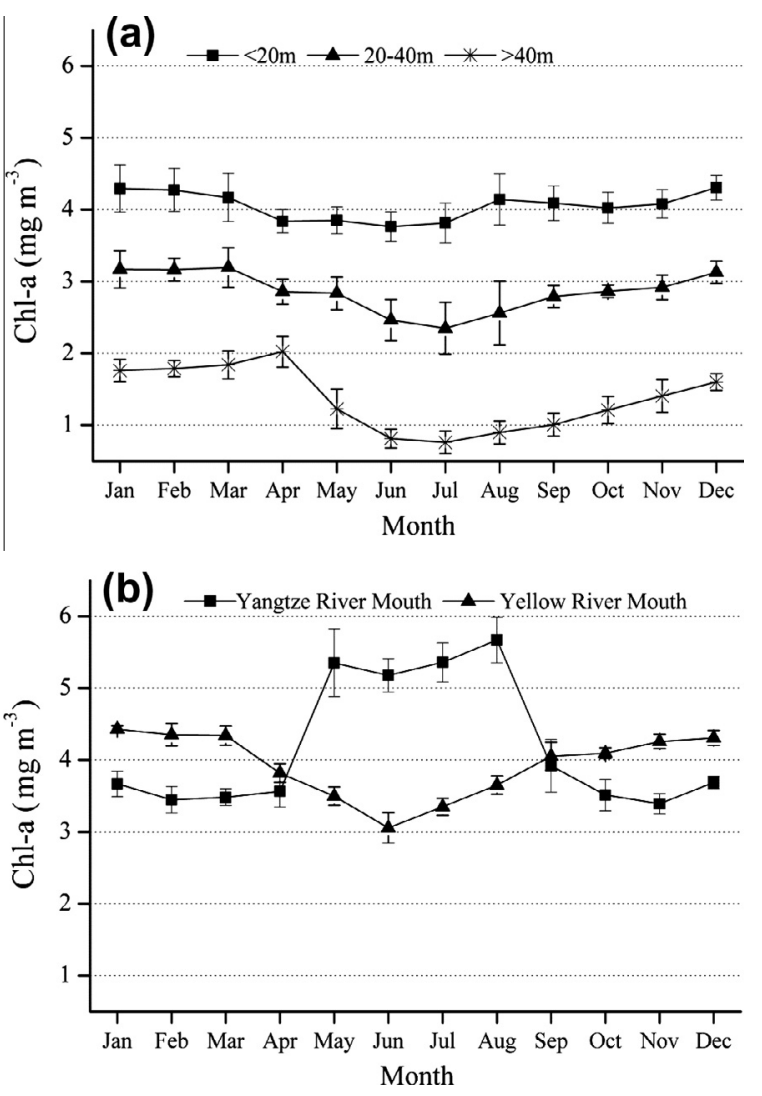

Fig. 7. Monthly climatological of Chl-a concentration averaged over different area (a) Averages over different depth ranges. (b) Averages at sampling locations at the Yangtze River Mouth and the Yellow River Mouth, shown in Fig. 1.

ern sea regions show higher temperature than the northern sea regions, particularly in winter and spring. For example, at the sea region near to Yangtze River mouth, winter-spring SST shows about a $5^{\circ}$ higher than at the sea region near to the Yellow River mouth (Fig. 9b).

SST inter-annual anomaly exhibits a general decreasing trend during 1998-2011 (Fig. 10). In a comparison, SST anomalies at the seas regions with water depth of $<40 \mathrm{~m}$ (Fig. 10a and b) are more variable and have more clear declining trends than the sea regions with water depth of $>40 \mathrm{~m}$ (Fig. 10c). The linear statistical analysis between Chl-a and SST anomalies show a significant positive correlation at the sea region with water depth of $<20 \mathrm{~m}$ (Fig. 11a), but a negative correlation at the sea region with water depth of $20-40 \mathrm{~m}$ and $>40 \mathrm{~m}$ (Fig. $11 \mathrm{~b}$ and c).

\section{Discussions}

\subsection{Providing confidence in the satellite Chl-a data}

The Bohai and Yellow Seas are characterized by optically-complex case II waters due to high suspended sediment, which can cause an overestimation of satellite derived Chl-a using global chlorophyll algorithms, particularly in the coastal waters (Gregg and Casey, 2004; IOCCG, 2000; Siswanto et al., 2011). Previous studies showed that the satellite-derived Chl-a values along the China coast are within the acceptable range because the correlations between retrieved and in situ measured Chl-a concentration are significant (Sun et al., 2010; Xiu et al., 2007; Zhang et al., 2006). A quantitative comparison between the SeaWiFS and the MODIS data sets displays a significant linear correlation in this study (Fig. 2a) and the cross-validation of DINEOF reconstruction 

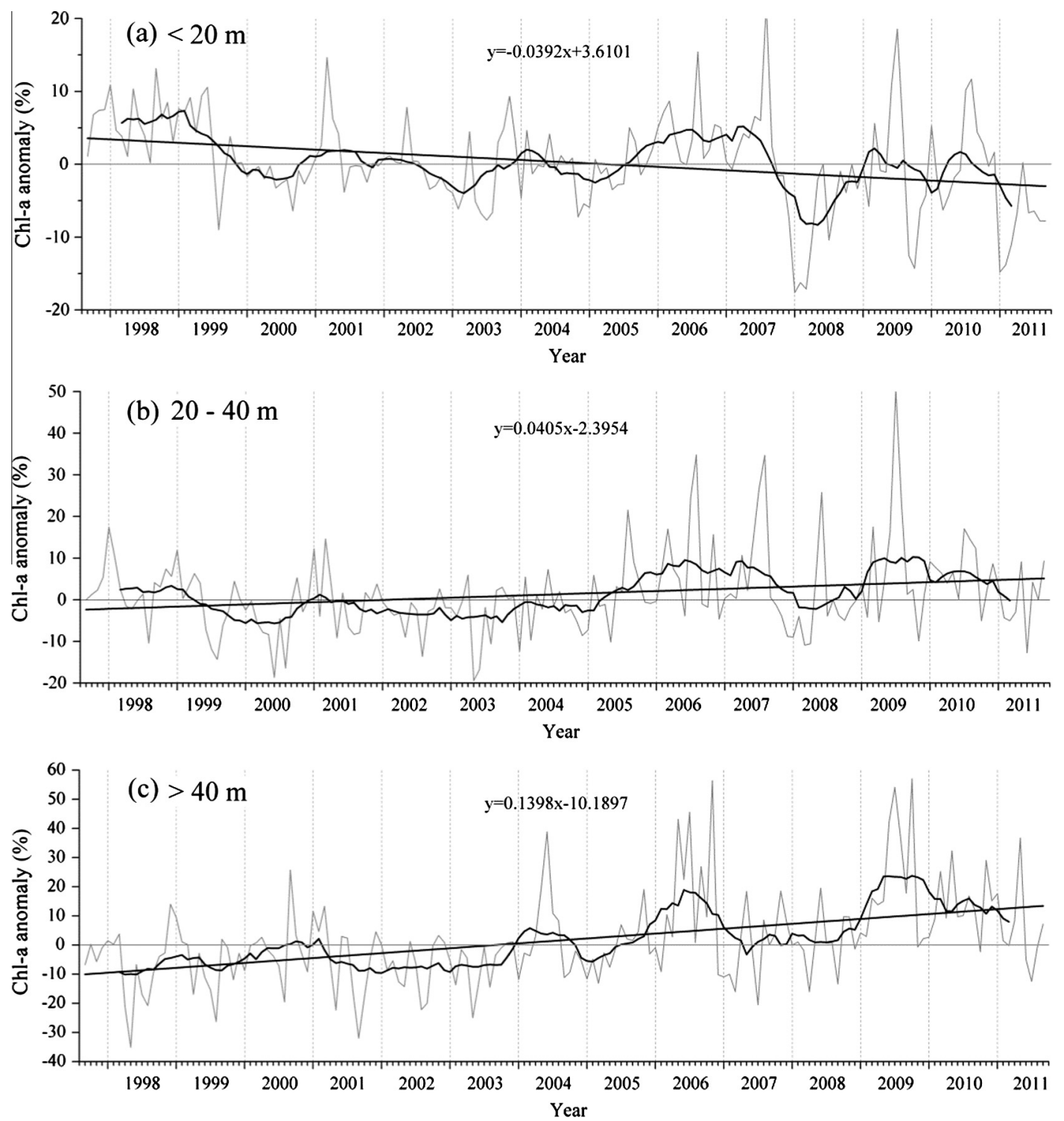

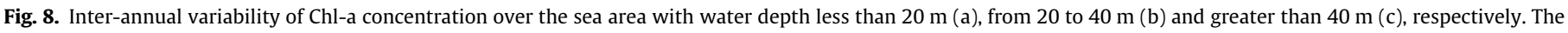
monthly Chl-a anomaly (gray line) with the 12-month running average line (black line) and the linear trend (straight line) are shown.

shows a smaller error (0.11 in log RMSE) than the algorithm "noise" (0.22 in log RMSE) accepted in O'Reilly et al. (2000). Moreover, compared with the satellite derived Chl-a data of the Bohai and Yellow Seas used in Shi and Wang (2012) and Yamaguchi et al. (2012), our data shows a similar range $\left(0.1-10 \mathrm{mg} \mathrm{m}^{-3}\right)$ in spatial and temporal pattern. Thus, this reconstructed cloud-free satellite Chl-a data is a valid basis for our study.

\subsection{Indications of Chl-a spatial and temporal patterns}

The results clearly show that different Chl-a seasonal and interannual patterns exist in coastal and offshore waters, following isobath in the Bohai and Yellow Seas. The related physical and chemical effects were discussed below for helping to understand these results.

\subsubsection{The spatial difference of Chl-a seasonal patterns in the Bohai and Yellow Seas}

A general Chl-a spatial pattern showed that the concentrations in the Bohai Sea were higher than in the Yellow Sea, and concentrations in coastal waters were higher than in offshore waters. It is consistent to the Chl-a in situ observations, Chl-a peaks are observed in the Bohai Bay and Laizhou Bay (Bohai Sea) (e.g., Wang and Kang, 1998), in the northern Yellow Sea and Jiaozhou Bay (southern Yellow Sea) (e.g., Gao, 2009; Liu, 2004), in the southwest of the Korea, East of Jeju Island and in Japan coastal waters (e.g., Yamada et al., 2004). Chl-a spatial pattern matches the spatial distribution of nutrients in the Bohai and Yellow Seas, with higher nutrient concentrations near shore but lower offshore (Lin et al., 2005; Wang et al., 2003; Wei et al., 2004; Yu et al., 2000). Numerous rivers and various agriculture and industry activities along the coastline have significantly contributed to high nutrient levels in coastal waters, particularly during the wet season (summer) as a result of increased land runoff and river input (Lin et al., 2005; Wang et al., 2003; Wei et al., 2004; Yu et al., 2000). Moreover, the geographic conditions can basically explain why the Chl-a concentrations in the Bohai Sea are higher than in the Yellow Sea (Fig. 1a). Compared with the Yellow Sea, the Bohai Sea is shallower and has a longer water exchange with the Yellow Sea due to the limitation of Bohai strait and thus a vertical well-mixed water and long retention time can increase nutrient concentrations and help phytoplankton growth (Guan, 1994; Wei et al., 2004). 

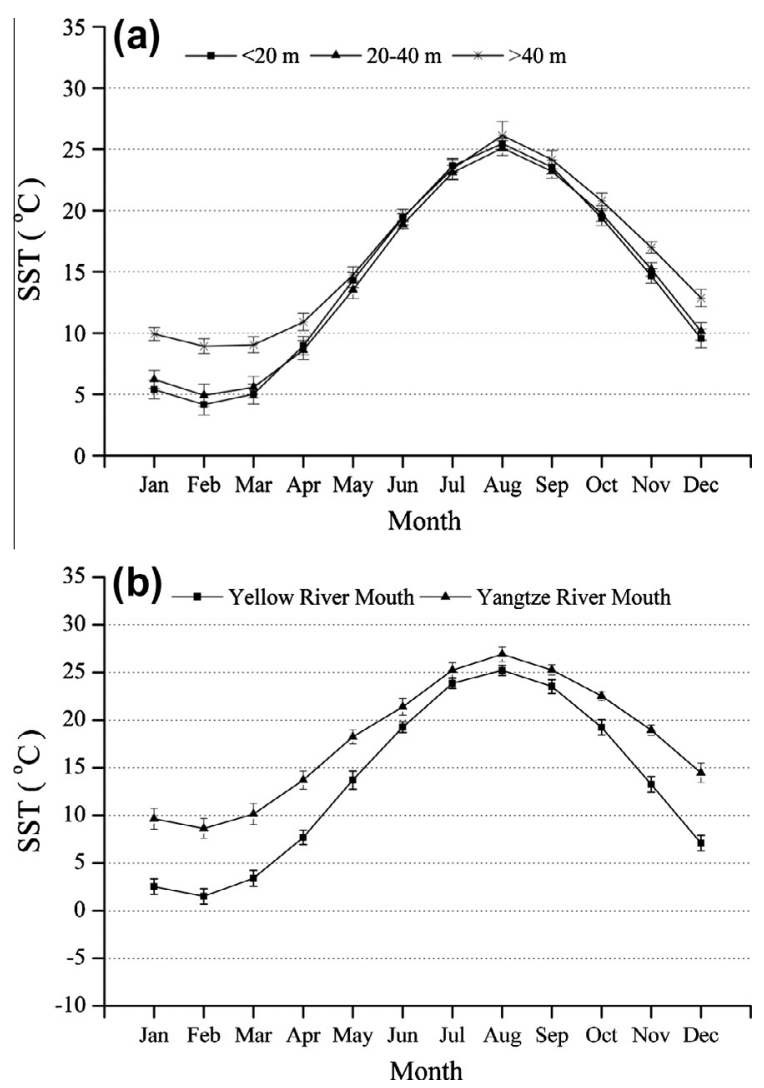

Fig. 9. Monthly climatological of SST averaged over different area. (a) Averages over different depth ranges. (b) Averages at sampling locations at the Yangtze River Mouth and the Yellow River Mouth, shown in Fig. 1.

Compared with the dominant Chl-a winter maximum (December-February) in coastal waters $(<20 \mathrm{~m})$, March maximum dominates in the water depth of $20-40 \mathrm{~m}$ and April maximum in offshore waters $(>40 \mathrm{~m})$ which indicated a time lag of $1-3(2.2 \pm 1.3)$ month between coastal and offshore waters (Fig. 7). Using SeaWiFS Chl-a data during 1997-2006, Yamaguchi et al. (2012) first pointed that there is a time lag of 0-2 month in the winter-spring Chl-a maximum between coastal and the central Yellow Sea. This is very close to our result. Almost no published report explains why there is a delay in Chl-a maximum between coastal and offshore waters. The seasonal variations of sea fronts in the Bohai and Yellow Seas may help us to understand this phenomenon. Hickox et al. (2000) found there are 10 fronts in the Bohai, Yellow and East China Seas including shelf-break fronts, shelf fronts and coastal fronts, and these fronts follow the 50-m isobath. Huang et al. (2010) further found that coastal fronts in the Yellow Sea are variable depending on their geographic locations and seasonal changes, and most of the fronts emerge in autumn and winter, fade in spring and disappear in summer, corresponding to the intensity of YSWC. For example, Shandong and Jiangsu coastal fronts reach their maximum in January and February when YSWC intense is strong; and then the frontal probability reduces due to the weakening YSWC in March and April (Huang et al., 2010). Shi and Wang (2012) also mentioned that ocean bathymetry in the Bohai and Yellow Seas plays a critical role on the spatial patterns of Chl-a and total suspended matter. These results indicated a potential link between the variations of frontal structures and Chl-a seasonal pattern.

The strong convection currents between coastal and offshore waters formed in some seasons can enhance the coastal nutrient transporting to offshore waters (Yuan and Hsueh, 2010; Yuan et al., 2008). In March and April, coastal nutrient transporting to the central Yellow Sea can be enhanced under the north-westerly wind action when coastal fronts weaken due to the reduced YSWC intensity. At the same time, the increased solar radiation and air temperature in March and April warmed up SST, gradually, and this can reduce the vertical mixing between surface and subsurface seawaters. These variations in physical processes can keep phytoplankton living longer in the upper euphotic layer and acquire sufficient nutrients and light for a fast growth resulting in a Chl-a maximum in the central Yellow Sea.

Compared with the seasonal pattern of two Chl-a peaks (winter and summer) in coastal waters, no summer maximum occurs in the central Yellow Sea. This could be related to the formation of YSCW in summer in the central Yellow Sea. Nutrients in the central Yellow Sea result mainly from the offshore transportation of coastal waters, atmospheric deposition and the vertical water exchange induced by upwelling. During summer, the dense YSCW is the dominant water mass in the central Yellow Sea and distributes below the thermocline, and thus it can significantly reduce the vertical mixture of nutrients between bottom and surface water in the central Yellow Sea (Naimie et al., 2001). YSCW is a basin-scale lowpressure system and cyclonic circulation (Su, 1998). Under this scenario, coastal currents would be directed northward along the Korean coast and southward along the Chinese coast (Naimie et al., 2001). This kind of circulation can weaken the horizontal nutrient exchange between coastal and offshore waters. Moreover, the prevalent south-easterly wind in summer also can slow down the nutrient exchange from coastal surface waters to the central Yellow Sea. These hydrodynamic mechanisms could play an important role to control the nutrient supply to the surface water in the central Yellow Sea, and this could limit the growth of phytoplankton and weaken the likelihood of a summer Chl-a maximum.

The Yangtze River adjacent sea area displayed a long-lasting summer Chl-a maximum from May to August (Fig. 7b). This well follows the timeline of summer monsoon rainy season in the eastern China. The summer monsoon rainy season over East Asia commonly begins in mid- or late-May along the coasts of eastern China, the Korean Peninsula and Japan and it ends in late July or early August (Qian et al., 2002); the autumn rainy season in the Korean Peninsula usually occurs between mid-August and mid-September (Qian et al., 2002). Increased land runoff acting to decrease salinity combined with warm coastal waters during wet season can significantly accelerate the phytoplankton growth and cause a long-lasting Chl-a maximum. Other evidence also confirmed this phenomenon. For example, Zhou et al. (2003) summarized the records of red tides in the sea area adjacent to the Yangtze River and found that most red tides occurred during May-September with about $60 \%$ of the total occurring in May; Yamaguchi et al. (2012) found a significant July Chl-a maximum in this region and attributed it to the maximum freshwater discharge in summer.

\subsubsection{The spatial difference in inter-annual trends of Chl-a in the Bohai and Yellow Seas}

A general inter-annual trend of the 14-years Chl-a anomaly displays a significant increase in offshore waters and a decrease in the coastal waters (Fig. 8). Yamaguchi et al. (2012) observed a similar increasing trend of Chl-a in offshore waters using SeaWiFS Chl-a during 1998-2010, and they thought it might be evidence of eutrophication from coastal to offshore waters. In this study, the increasing trend of Chl-a and decreasing trend of SST in the offshore waters shows a significant negative correlation (Fig. 11c). Several studies have found that surface warming in permanently stratified ocean regions is accompanied by reductions in sea surface Chl-a, the result of weakening vertical mixing due to the increase in density stratification between the surface layer and underlying nutrient-rich waters (e.g., Behrenfeld et al., 2006; Boyce et al., 2010). It offers an explanation to help us for understanding 

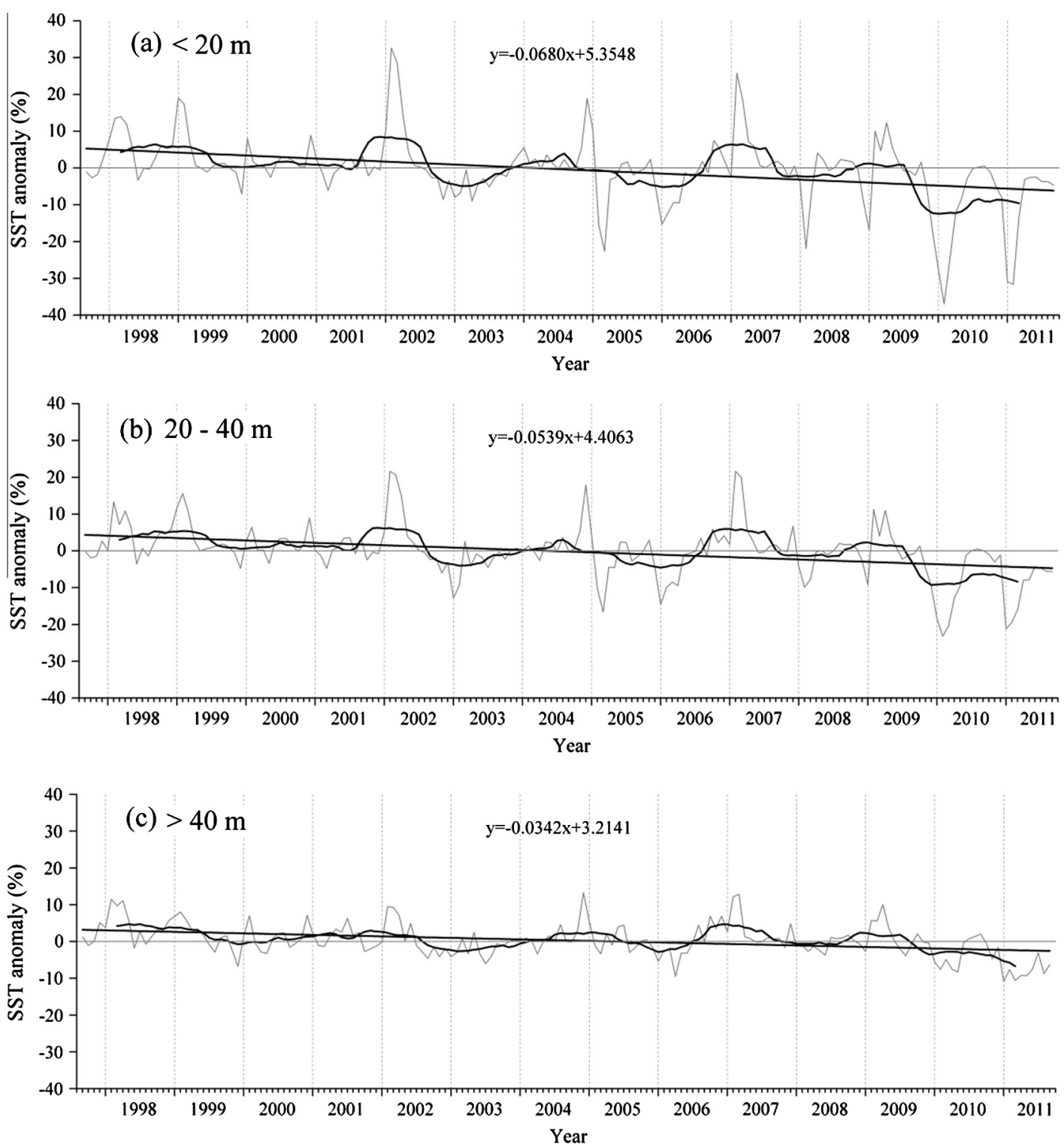

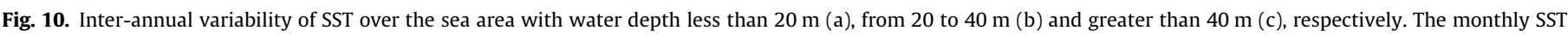
anomaly (gray line) with the 12-month running average line (black line) and the linear trend (straight line) are shown.

the correlation between the increasing trend of Chl-a and decreasing trend of SST in offshore waters, particularly in the central Yellow Sea with permanent stratification.

In a comparison, decreasing trend of Chl-a in coastal waters $(<20 \mathrm{~m})$ shows a significantly positive correlation with decreasing trend of SST. The hydrodynamics in coastal waters are dominated by the variation of wind-tide-thermohaline circulations, and thus the water body can mix well in winter and only has a weak stratification in summer (Guan, 1994). In some degree, decreasing trend of SST could result in the decrease of Chl-a. However, the trend of rising SST and decreasing Chl-a in the Bohai Sea over the period of 1960s-1990s were observed according to the data at six coastal monitoring stations (Jin and Tang, 1998; Lin et al., 2001). The phenomenon also occurred in the Yellow Sea over the period of 19762000 , corresponding to the rise of the mean air temperature throughout the Northern Hemisphere (Houghton et al., 1996; Yan and Li, 1997; Lin et al., 2005). These results indicated the inter-annual variability of Chl-a in coastal waters is more complicated than in offshore waters.
Eutrophication was proposed by many scientist as other important factors controlling phytoplankton biomass in coastal waters (e.g., Su and Tang, 2002; Tang et al., 2003; Wang et al., 2003; Liu et al., 2005). Eutrophication caused by excessive nitrogen in coastal waters has altered nutrient structure. The dissolved silicate (DSi: an essential nutrient for diatoms) cannot increase as fast as nitrogen and this can result in Si-limitation for diatom growth, a major phytoplankton assemblage in the Bohai and Yellow Sea. Moreover, significantly less freshwater input due to damming not only can reduce $\mathrm{Si}$ input but also increase salinity, and these were observed in large river mouth. One example is the three gorge dam impounded in the Yangtze River since 2003. Decreased nutrient and primary productivity associated with freshwater discharge reduction during the first phase of water storage were observed (Gong et al., 2006; Jiao et al., 2007). The other example is increased dams in the Yellow River. By 2001, more than 3147 reservoirs had been built in the Yellow River basin, with a total storage capacity of $57.4 \times 10^{9} \mathrm{~m}^{3}$ (Zhang et al., 2001); and since 2002, the Xiaolangdi reservoir was built as a major regulator for water storage, with a 
(a) $<20 \mathrm{~m}$

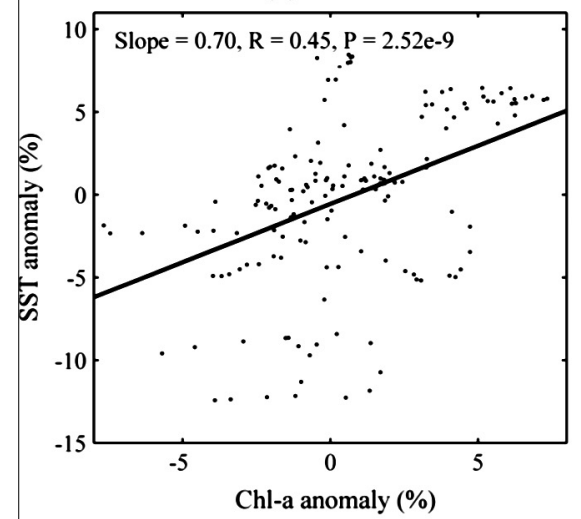

(b) $20-40 \mathrm{~m}$

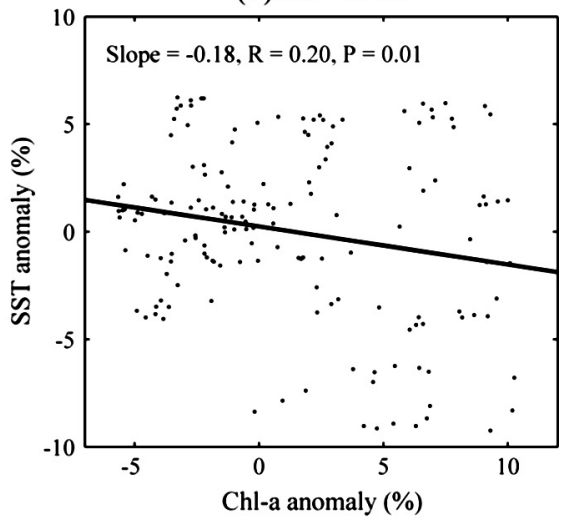

(c) $>40 \mathrm{~m}$

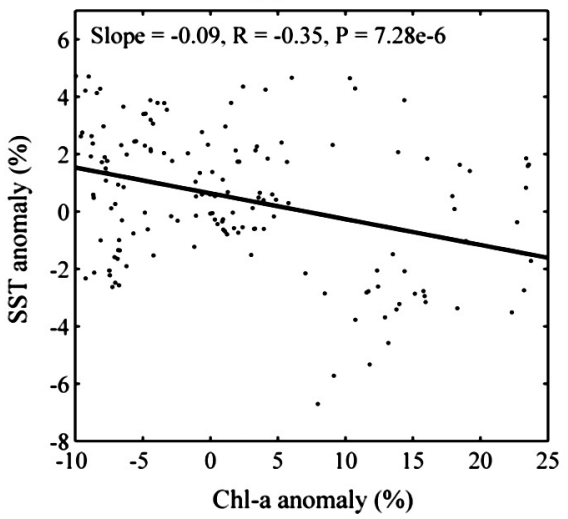

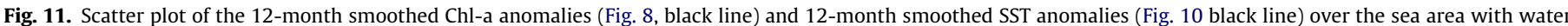
depth less than $20 \mathrm{~m}$ (a), from 20 to $40 \mathrm{~m}$ (b) and greater than $40 \mathrm{~m}$ (c). Solid lines indicate linear regression fit.

total capacity of $12.7 \times 10^{9} \mathrm{~m}^{3}$ (Wang et al., 2006). During 20042009, sea surface salinity in most parts of the Bohai Sea showed increasing trend and the Yellow River discharge was found to have the greatest influence on sea surface salinity near the river estuary (Qing et al., 2013). These significant environmental changes indicated the complexity of Chl-a variability in coastal waters.

\section{Concluding remarks}

In this study, different seasonal and inter-annual patterns existing between coastal and offshore waters were distinguished, linked to bathymetry in the Bohai and Yellow Seas. Two seasonal peaks (winter and late summer) dominate in coastal waters (depth $<20 \mathrm{~m}$ ); One spring peak (March-April) dominate in offshore waters (depth $>40 \mathrm{~m}$ ), indicated a time lag of $0-3$ months relative to coastal waters; and Sea areas with water depth $20-40 \mathrm{~m}$ indicated a mixing or transitional feature between coastal and offshore waters. The adjacent sea region at the Yangtze River mouth displayed a long-lasting summer peak (May-September), consistent with the East Asia summer monsoon rainy season. Inter-annual patterns of Chl-a in the 14-year period showed a decreasing trend in coastal but an increasing trend in offshore waters.

In offshore waters, the impact on the circulation of the YSWC in winter and YSCW in summer in the central Yellow Sea could be a key physical factor in explaining the variability of Chl-a in seasonal and inter-annual patterns. In coastal waters, wind-tide-thermohaline circulations and East Asia monsoon impact the nutrient mixture and Chl-a variability in seasonal and inter-annual patterns, but increased human activity (e.g., eutrophication, dam) could significantly enhance this process.

\section{Acknowledgements}

We appreciate for the comments and language editing from Dr. Roger Proctor in University of Tasmania, Australia. The study was funded by Natural Science Foundation of China (No. 40976097) and the Strategic Priority Research Program of Chinese Academy of Sciences (No. XDA05130703). The SeaWiFS and MODIS/Aqua L3 chlorophyll-a products were obtained from NASA/GSFC ocean color website.

\section{References}

Alvera-Azcarate, A., Barth, A., Rixen, M., Beckers, J.M., 2005. Reconstruction of incomplete oceanographic data sets using empirical orthogonal functions: application to the Adriatic Sea surface temperature. Ocean Modelling 9, 325346.

Beckers, J.M., Rixen, M., 2003. EOF calculations and data filling from incomplete oceanographic datasets. Journal of Atmospheric and Oceanic Technology 20 1839-1856.

Beckers, J.-M., Barth, A., Alvera, A., 2006. DINEOF Reconstruction of Clouded Images Including Error Maps. Application to the Sea-Surface Temperature around Corsican Island. European Geosciences Union.

Behrenfeld, M.J., O’Malley, R.T., Siegel, D.A., McClain, C.R., Sarmiento, J.L., Feldman, G.C., Milligan, A.J., Falkowski, P.G., Letelier, R.M., Boss, E.S., 2006. Climate-driven trends in contemporary ocean productivity. Nature 444, 752-755.

Boyce, D.G., Lewis, M.R., Worm, B., 2010. Global phytoplankton decline over the past century. Nature 466, 591-596.

Campbell, J.W., 1995. The lognormal distribution as a model for bio-optica variability in the sea. Journal of Geophysical Research 100,13237-13254.

Chassot, E., Bonhommeau, S., Dulvy, N.K., Mélin, F., Watson, R., Gascuel, D., Le Pape, O., 2010. Global marine primary production constrains fisheries catches. Ecology Letters 13, 495-505.

de Jonge, V., Elliott, M., Orive, E., 2002. Causes, historical development, effects and future challenges of a common environmental problem: eutrophication. Hydrobiologia 475-476, 1-19. 
Falkowski, P.G., Oliver, M.J., 2007. Mix and match: how climate selects phytoplankton. Nature Reviews Microbiology 5, 813-819.

Falkowski, P.G., Barber, R.T., Smetacek, V., 1998. Biogeochemical controls and feedbacks on ocean primary production. Science 281, 200-206.

Field, C.B., Behrenfeld, M.J., Randerson, J.T., Falkowski, P., 1998. Primary production of the biosphere: integrating terrestrial and oceanic components. Science 281, 237-240.

Gao, S., 2009. Spatial and Seasonal Variation of Chlorophyll and Primary Productivity and their Controlling Factors in the Northern Yellow Sea. Master Thesis, Ocean University of China (in Chinese with English abstract).

Gong, G.C., Wen, Y.H., Wang, B.W., Liu, G.J., 2003. Seasonal variation of chlorophyll a concentration, primary production and environmental conditions in the subtropical East China Sea. Deep Sea Research Part II: Topical Studies in Oceanography 50, 1219-1236.

Gong, G.C., Chang, J., Chiang, K.P., Hsiung, T.M., Hung, C.C., Duan, S.W., Codispoti, L.A., 2006. Reduction of primary production and changing of nutrient ratio in the East China Sea: effect of the Three Gorges Dam? Geophysical Research Letters 33, L07610.

Gregg, W.W., Casey, N.W., 2004. Global and regional evaluation of the SeaWiFS chlorophyll data set. Remote Sensing of Environment 93, 463-479.

Gregg, W.W., Conkright, M.E., Ginoux, P., O’Reilly, J.E., Casey, N.W., 2003. Ocean primary production and climate: global decadal changes. Geophysical Research Letters 30, 1809.

Gregg, W.W., Casey, N.W., McClain, C.R., 2005. Recent trends in global ocean chlorophyll. Geophysical Research Letters 32, L03606.

Guan, B., 1994. Patterns and structures of the currents in Bohai, Huanghai and East China Sea. In: Zhou, D., Liang, Y., Tseng, C. (Eds.), Oceanology of China Sea. Kluwer Academic Publishers, The Netherlands, pp. 17-26.

Harley, C.D.G., Randall Hughes, A., Hultgren, K.M., Miner, B.G., Sorte, C.J.B., Thornber C.S., Rodriguez, L.F., Tomanek, L., Williams, S.L., 2006. The impacts of climate change in coastal marine systems. Ecology Letters 9, 228-241.

He, X.Q., Bai, Y., Pan, D., Chen, C., Wang, D.F., Gong, F., 2013. Satellite views of seasonal and inter-annual variability of phytoplankton blooms in the eastern China seas over the past $14 \mathrm{yr}$ (1998-2011). Biogeosciences Discussions 10 111-155.

Hickox, R., Belkin, I., Cornillon, P., Shan, Z., 2000. Climatology and seasonal variability of ocean fronts in the East China, Yellow and Bohai Seas from satellite SST data. Geophysical Research Letters 27, 2945-2948.

Houghton, J.T., Meira Filho, L.G., Callander, B.A., Harris, N., Kattenberg, A., Maskell, K. (Eds.), 1996. Climate Change 1995. Cambridge University Press Published for the Intergovernmental Panel on Climate Change.

Huang, D., Zhang, T., Zhou, F., 2010. Sea-surface temperature fronts in the Yellow and East China Seas from TRMM microwave imager data. Deep Sea Research Part II: Topical Studies in Oceanography 57, 1017-1024.

IOCCG, 2000. Remote sensing of ocean colour in coastal and other optically complex waters. In: Reports of the International Ocean-Colour Coordination Group, vol. 3. IOCCG, Dartmouth, Canada, p. 140.

Jiao, N., Zhang, Y., Zeng, Y., Gardner, W.D., Mishonov, A.V., Richardson, M.J., Hong, N. Pan, D., Yan, X.-H., Jo, Y.-H., Chen, C.-T.A., Wang, P., Chen, Y., Hong, H., Bai, Y., Chen, X., Huang, B., Deng, H., Shi, Y., Yang, D., 2007. Ecological anomalies in the East China Sea: impacts of the Three Gorges Dam? Water Research 41, 12871293.

Jin, X., Tang, Q., 1998. The structure, distribution and variation of the fishery resources in the Bohai Sea. Journal of Fishery Sciences of China 5, 18-24 (in Chinese).

Krishna, K.M., 2010. Variability of SeaWiFS-derived chlorophyll-a concentrations in waters off central east coast of India, 1998-2003. International Journal of Applied Earth Observation and Geoinformation 12, 101-109.

Lie, H., Cho, C., Lee, S., 2009. Tongue-shaped frontal structure and warm water intrusion in the southern Yellow Sea in winter. Journal of Geophysical Research: Oceans 114, C01003.

Lin, C., Su, J., Xu, B., Tang, Q., 2001. Long-term variations of temperature and salinity of the Bohai Sea and their influence on its ecosystem. Progress in Oceanography 49, 7-19.

Lin, C., Ning, X., Su, J., Lin, Y., Xu, B., 2005. Environmental changes and the responses of the ecosystems of the Yellow Sea during 1976-2000. Journal of Marine Systems 55, 223-234.

Liu, D., 2004. Community Structure Succession Study of Phytoplankton and Sediment Diatom in Jiaozhou Bay. vol. Dissertation. Ocean University of China, Qingdao (in Chinese with English abstract).

Liu, G.M., Sun, S., Wang, H., Zhang, Y., Yang, B., Ji, P., 2003. Abundance of Calanus sinicus across the tidal front in the Yellow Sea, China. Fisheries Oceanography 12, 291-298

Liu, S.M., Zhang, J., Chen, H.T., Zhang, G.S., 2005. Factors influencing nutrient dynamics in the eutrophic Jiaozhou Bay, North China. Progress in Oceanography $66,66-85$.

Mask, A.C., O’Brien, J.J., Preller, R., 1998. Wind-driven effects on the Yellow Sea Warm Current. Journal of Geophysical Research 103, 30713-30729.

Naimie, C., Ann Blain, C.R., Lynch, D., 2001. Seasonal mean circulation in the Yellow Sea-a model-generated climatology. Continental Shelf Research 21, 667-695.

Navarro, G., Ruiz, J., 2006. Spatial and temporal variability of phytoplankton in the Gulf of Cadiz through remote sensing images. Deep Sea Research Part II: Topica Studies in Oceanography 53, 1241-1260.

Nitani, H., 1972. Beginning of the Kuroshio. Kuroshio, Its Physical Aspects, 129-163.
O’Reilly, J.E., Maritorena, S., Mitchell, B.G., Siegel, D.A., Carder, K.L., Garver, S.A., Kahru, M., McClain, C., 1998. Ocean color chlorophyll algorithms for SeaWiFS. Journal of Geophysical Research 103, 24937-24953.

O’Reilly, J.E., Maritorena, S., Siegel, D.A., O’Brien, M.C., Toole, D., Mitchell, B.G., Kahru, M., Chavez, F.P., Strutton, P., Cota, G.F., Hooker, S.B., McClain, C.r., Carder, K.L., Muller-Karger, F., Harding, L., Magnuson, A., Phinney, D., Moore, G.F., Aiken, J., Arrigo, K.R., Letelier, R., Culver, M., 2000. Ocean color chlorophyll a algorithms for SeaWiFS, OC2, and OC4: Version 4. In: Hooker, S.B., Firestone, E.R. (Eds.), NASA Technical Memorandum 2000-206892, vol. 11. NASA-GSFC, Greenbelt, Maryland, pp. 9-23 (Chapter 2).

Qian, W., Kang, H.S., Lee, D.K., 2002. Distribution of seasonal rainfall in the East Asian monsoon region. Theoretical and Applied Climatology 73, 151-168.

Qing, S., Zhang, J., Cui, T., Bao, Y., 2013. Retrieval of sea surface salinity with MERIS and MODIS data in the Bohai Sea. Remote Sensing of Environment 136, 117125 .

Radiarta, I.N., Saitoh, S.I., 2008. Satellite-derived measurements of spatial and temporal chlorophyll-a variability in Funka Bay, southwestern Hokkaido, Japan. Estuarine, Coastal and Shelf Science 79, 400-408.

Reynolds, R.W., Smith, T.M., Liu, C., Chelton, D.B., Casey, K.S., Schlax, M.G., 2007. Daily high-resolution-blended analyses for sea surface temperature. Journal of Climate 20, 5473-5496.

Saitoh, S., Iida, T., Sasaoka, K., 2002. A description of temporal and spatial variability in the Bering Sea spring phytoplankton blooms (1997-1999) using satellite multi-sensor remote sensing. Progress in Oceanography 55, 131-146.

Shi, W., Wang, M., 2010. Characterization of global ocean turbidity from Moderate Resolution Imaging Spectroradiometer ocean color observations. Journal of Geophysical Research 115, C11022.

Shi, W., Wang, M., 2012. Satellite views of the Bohai Sea, Yellow Sea, and East China Sea. Progress in Oceanography 104, 30-45.

Siswanto, E., Tang, J., Yamaguchi, H., Ahn, Y.H., Ishizaka, J., Yoo, S., Kim, S.W., Kiyomoto, Y., Yamada, K., Chiang, C., Kawamura, H., 2011. Empirical ocean-color algorithms to retrieve chlorophyll-a, total suspended matter, and colored dissolved organic matter absorption coefficient in the Yellow and East China Seas. Journal of Oceanography 67, 627-650.

Smetacek, V., Cleorn, J.E., 2008. On phytoplankton trends. Science 319, 1346-1348.

Su, J.L., 1998. Circulation dynamics of the China Seas north of 180 N. In: Robinson, A.R., Brink, K.H. (Eds.), The Sea, vol. 11. John Wiley \& Sons Inc., New York, pp. 483-505.

Su, J.L., Tang, Q.S., 2002. Study on Ecosystem Dynamics in China Sea. II. Processes of the Bohai Sea Ecosystem Dynamics. China Science Press, Beijing.

Sun, L., Guo, M., Wang, X., 2010. Ocean color products retrieval and validation around China coast with MODIS. Springer, Heidelberg, ALLEMAGNE.

Tang, Q., Jin, X., Wang, J., Zhuang, Z., Cui, Y., Meng, T., 2003. Decadal-scale variations of ecosystem productivity and control mechanisms in the Bohai Sea. Fisheries Oceanography 12, 223-233.

Tang, D.L., Di, B.P., Wei, G.f., Ni, I.H., Oh, I., Wang, S.F., 2006. Spatial, seasonal and species variations of harmful algal blooms in the South Yellow Sea and East China Sea. Hydrobiologia 568, 245-253.

Tian, T., Wei, H., Su, J., Chung, C., 2005. Simulations of annual cycle of phytoplankton production and the utilization of nitrogen in the Yellow Sea. Journal of Oceanography $61,343-357$.

Uda, M., 1934. The results of simultaneous oceanographical investigations in the Japan Sea and its adjacent waters in May and June, 1932. Journal of the Imperial Fishery Expedition Station 5, 157-190.

Volpe, G., Nardelli, B.B., Cipollini, P., Santoleri, R., Robinson, I.S., 2011. Seasonal to interannual phytoplankton response to physical processes in the Mediterranean Sea from satellite observations. Remote Sensing of Environment 117, 223-235.

Wang, J., Kang, Y., 1998. Study on population dynamics of phytoplankton in the Bohai Sea. Marine Fisheries Research 19, 43-52 (in Chinese with English abstract).

Wang, M., Shi, W., 2007. The NIR-SWIR combined atmospheric correction approach for MODIS ocean color data processing. Optics Express 15, 15722-15733.

Wang, B., Wang, X., Zhan, R., 2003. Nutrient conditions in the Yellow Sea and the East China Sea. Estuarine, Coastal and Shelf Science 58, 127-136.

Wang, H., Yang, Z., Saito, Y., Liu, J.P., Sun, X., 2006. Interannual and seasonal variation of the Huanghe (Yellow River) water discharge over the past 50 years: connections to impacts from ENSO events and dams. Global and Planetary Change 50, 212-225.

Wei, H., Sun, J., Moll, A., Zhao, L., 2004. Phytoplankton dynamics in the Bohai Seaobservations and modelling. Journal of Marine Systems 44, 233-251.

Xiu, P., Liu, Y., Rong, Z., Zong, H., Li, G., Xing, X., Cheng, Y., 2007. Comparison of chlorophyll algorithms in the Bohai Sea of China. Ocean Science Journal 42 199-209.

Yamada, K., Ishizaka, J., Yoo, S., Kim, H., Chiba, S., 2004. Seasonal and interannual variability of sea surface chlorophyll a concentration in the Japan/East Sea (JES). Progress in Oceanography 61, 193-211.

Yamaguchi, H., Kim, H.-C., Son, Y.B., Kim, S.W., Okamura, K., Kiyomoto, Y., Ishizaka, J., 2012. Seasonal and summer interannual variations of SeaWiFS chlorophyll a in the Yellow Sea and East China Sea. Progress in Oceanography 105, 22-29.

Yan, J., Li, J., 1997. The climate change in the last 100 years over the East China Sea and its adjacent region. Acta Oceanologica Sinica 19, 121-126 (in Chinese).

Yu, Z.G., Mi, T.Z., Xie, B.D., Yao, Q.Z., Zhang, J., 2000. Changes of the environmental parameters and their relationship in recent twenty years in the Bohai Sea. Marine Environmental Science 19, 15-19 (in Chinese with English abstract). 
Yuan, D., Hsueh, Y., 2010. Dynamics of the cross-shelf circulation in the Yellow and East China Seas in winter. Deep Sea Research Part II: Topical Studies in Oceanography $57,1745-1761$.

Yuan, D., Zhu, J., Li, C., Hu, D., 2008. Cross-shelf circulation in the Yellow and East China Seas indicated by MODIS satellite observations. Journal of Marine Systems 70, 134-149.

Zar, J.H., 1999. Biostatistical Analysis. Prentice-Hall, Upper Saddle River, New Jersey. Zhang, X., Wang, L, Si, F, 2001. Prediction of water consumption in the Huanghe river basin. Water Resources and Hydropower Technology 6, 8-13 (in Chinese).
Zhang, C., Hu, C., Shang, S., Müller-Karger, F.E., Li, Y., Dai, M., Huang, B., Ning, X. Hong, H., 2006. Bridging between SeaWiFS and MODIS for continuity of chlorophyll-a concentration assessments off Southeastern China. Remote Sensing of Environment 102, 250-263.

Zhou, M. Yan, T., Zou, J., 2003. Preliminary analysis of the characteristics of redtide areas in the Changjiang River Estuary and its adjacent sea. Chinese Journal of Applied Ecology 14, 1031-1038 (in chinese). 